\title{
ORIGINAL ARTICLE \\ Metabolic and histopathological effects of sleeve gastrectomy and gastric plication: an experimental rodent model
}

\author{
Osman Bilgin Gulcicek'*, Kamil Ozdogan', Ali Solmaz', Hakan Yigitbas', Serdar Altınay², \\ Aysegul Gunes ${ }^{3}$, Duygu Sultan Celik', Erkan Yavuz', Atilla Celik' and Fatih Celebi' \\ 'General Surgery Clinic, Bagcilar Training and Research Hospital, Istanbul, Turkey; ${ }^{2}$ Pathology Clinic, Bagcilar Training \\ and Research Hospital, Istanbul, Turkey; ${ }^{3}$ Biochemistry Clinic, Bagcilar Training and Research Hospital, Istanbul, Turkey; \\ ${ }^{4}$ Veterinary Medicine, Bagcilar Training and Research Hospital, Istanbul, Turkey
}

Abstract

Introduction: Obesity has recently become a major health problem, and researchers have been directed to work toward the development of surgical techniques, with new mediators playing an important role in nutrition. Gastric plication (GP) and sleeve gastrectomy (SG) have become popular recently. These are widely used techniques in bariatric surgery.

Objectives: In this study, we aimed to compare the efficiency of SG and GP techniques on rats.

Methods: Wistar-Hannover rats $(n=18)$ were divided into three equal groups, namely SG, GP, and control. Blood samples were taken before the operation and on the 30th day after the operation. The weights of all rats were recorded both on first day and the 30th day after the operation. Serum gastrin, ghrelin, and leptin levels were also measured on the same days. For histopathological examination, gastrectomy was performed after the animals were sacrificed.

Results: Average weight loss was 10\% for the SG group and 6.5\% for the GP group. One month after the operations, the decrease in the ghrelin and leptin levels of GP and SG groups was significant compared with the levels of the control group. Gastrin levels of the SG group increased significantly compared with those of the control group. Histopathological examination revealed that there was significant decrease in the ghrelin and leptin levels of the GP and SG groups compared with those of the control group. Foveolar hyperplasia (FH), cystic glandular dilatation, and fibrosis were significantly higher in the GP and SG groups compared with the control group.

Conclusion: Although GP is not as effective as SG in terms of weight loss, it provides the same effectiveness in decreasing ghrelin and leptin levels. Histopathological findings revealed that FH, fibrosis, and the cystic glandular dilatation development rates were similar.

Keywords: obesity; sleeve gastrectomy; gastric plication

Received: 2 January 2016; Revised: 29 January 2016; Accepted: 18 February 2016; Published: 15 April 2016

$\mathrm{O}$ besity is defined as the accumulation of abnormal or excessive fat tissue which impairs health, resulting in cardiovascular system diseases, diabetes mellitus, metabolic syndrome, musculoskeletal disorders, and psychiatric problems. Furthermore, obesity is recognized as a major health problem today $(1,2)$.

It has been suggested that obesity is a major threat to humanity, an assertion that has been seconded by the World Health Organization (3). Patients with a body mass index (BMI) of over $40 \mathrm{~kg} / \mathrm{m}^{2}$ are considered morbidly obese (4).

Diet, changes in habits, and medical treatment are non-surgical modalities to treat obesity, although with limited effect on weight loss. As such, there is no effective, long-term treatment for obesity (5). However, surgery is considered to be effective in managing obesity, and sleeve gastrectomy (SG), gastric bypass, gastric banding, and gastric plication (GP) are the most common procedures (6). There are many studies in the literature indicating that SG and GP involve simpler techniques, fewer complications, and higher efficiency compared with other techniques (7).

In this study, we aimed to compare the metabolic efficiency and histopathological results of both restrictive surgical methods: SG and GP.

\section{Materials and methods}

\section{Experimental design}

Eighteen Wistar-Hannover rats (600-700 g), provided by the Bagcilar Training and Research Hospital Animal 
Center (BADABEM), were used in this study. All animals were housed in cages (six rats in each cage) under controlled room temperature $22\left( \pm 2{ }^{\circ} \mathrm{C}\right)$, humidity $(60-70 \%)$, with 12-h light-dark schedule. They were fed with pellets, ad libitum, containing 21\% protein (MBD Animal Feed, Kocaeli, Turkey). All experimental procedures were approved by the Bagcilar Training and Research Hospital Animal Care and Use Committee (2014/02).

\section{Study groups}

Rats were grouped randomly as group 1 (control group, $n=6$ ), group 2 (SG group, $n=6$ ), and group 3 (GP group, $n=6)$. All rats were sacrificed using high-dose ketamine after 30 days of operation. Blood samples from all animals were taken by intracardiac puncture, and biochemical parameters (gastrin, ghrelin, and leptin) were measured. After midline laparotomy, a total gastrectomy was done, and the specimens were fixed in $10 \%$ formaldehyde for histopathological examination.

\section{Operative procedure}

The abdominal part of all rats was shaved under Isoflurane (Baxter, Puerto Rico, USA) inhalation anesthesia ( $5 \%$ for induction and $1-2 \%$ for maintenance), following the provision of antisepsis by $10 \%$ povidone iodine solution (Betadine ${ }^{\circledR}$ ). The initial weight of all rats was measured and recorded. Blood samples $(1 \mathrm{ml})$ were taken from an internal jugular vein for the biochemical parameters (gastrin, ghrelin, and leptin).

A 3-cm midline incision was done under sterile conditions. The abdomen was closed after exploration of the stomach in the control group. Fifty-to-seventy percent of the stomachs were excised after the dissection of gastrocolic and gastrosplenic ligaments from just $0.5 \mathrm{~cm}$ proximal to the pylorus to diaphragmatic crus in the SG group. Then, the inner layer was closed by continuous 5/0 polypropylene sutures (Dogsan, Trabzon, Turkey), and the outer layer was closed with continuous extramucosal sutures by $5 / 0$ polypropylene (Fig. 1a).
The same steps, up to the resection, were also performed on the GP group. After dissection of the ligaments, plication of the greater curvature was done with two-layered continuous extramucosal sutures by $5 / 0$ polypropylene (Dogsan) (Fig. 1b).

All surgical procedures were performed by the same surgeon. The abdominal incisions of all rats were closed by single layered non-continuous $2 / 0$ silk sutures (Dogsan). Thirty days after the operation, all rats were sacrificed using high-dose ketamine anesthesia (ketamine hydrochloride $50 \mathrm{mg} / \mathrm{kg}$; Ketalar ${ }^{\circledR}$, Parke-Davis, İstanbul, Turkey, and xylazine $10 \mathrm{mg} / \mathrm{kg}$; Rompun ${ }^{\circledR}$, Bayer, İstanbul, Turkey).

\section{Biochemical analysis}

Ghrelin, gastrin, and leptin levels were measured before and 30 days after the operations. Samples and the kit (Eastbiopharme Co., Ltd., Hangzhou, China) were brought to room temperature. First, $24 \mathrm{ng} / \mathrm{ml}$ stock was obtained by standard serial dilution from 6 standard kit. Standards $(50 \mu \mathrm{l})$ were added on the antibody-coated micro-plate wells. Then 50- $\mu$ l streptavidin-HRP was placed on thumbnail standards. After pipetting of standards on a micro-plate, serum samples were pipetted as $40 \mu \mathrm{l}$ on each micro-well. Leptin antibody, ghrelin antibody, and gastrin antibody of $10-\mu 1$ and $50-\mu 1$ streptavidinHRP were added on serum samples. The micro-plates were covered and left at $37^{\circ} \mathrm{C}$ incubation for $60 \mathrm{~min}$. After preparing the washing-solution $30 \times$, ELISA plates were washed five times in $350 \mu \mathrm{l}$ of washer. Fifty microliters of Chromogenic Solution A and Chromogenic Solution B were pipetted in each micro-well. Incubation was done at $37^{\circ} \mathrm{C}$ for $10 \mathrm{~min}$ in dark. Fifty microliters of Stop Solution were added on each micro-well. Micro-plate absorbance was measured at $450 \mathrm{~nm}$ for $10 \mathrm{~min}$.

\section{Histological analysis}

The resected specimens of the rats were fixed for pathologic evaluation in $10 \%$ buffered formaldehyde solution
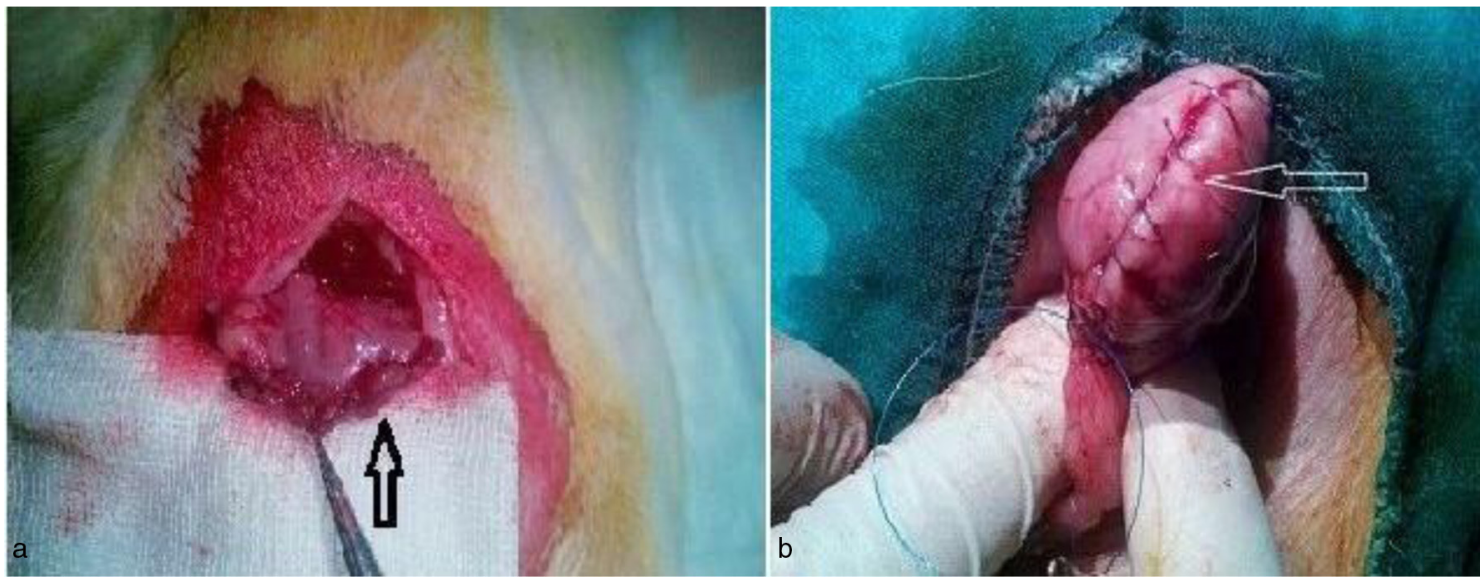

Fig. 1. (a) Sleeve gastrectomy. The arrow shows the gastrectomy line. (b) Gastric plication. The arrow shows the plication line. 
Table 1. Gastrin, ghrelin, and leptin levels

\begin{tabular}{llccrr}
\hline & & Control group & SG group & GP group & $P$ \\
\hline Gastrin $(\mathrm{ng} / \mathrm{ml})$ & Preop & $39.47 \pm 3.34$ & $39.98 \pm 4.5$ & $42.32 \pm 4.55$ & 0.469 \\
& Postop & $38.26 \pm 2.49$ & $43.16 \pm 2.68$ & $42.36 \pm 4.27$ & $\mathbf{0 . 0 4 3}$ \\
Ghrelin $(\mathrm{ng} / \mathrm{ml})$ & Preop & $12.81 \pm 0.69$ & $16.73 \pm 1.25$ & $13.05 \pm 1.83$ & $\mathbf{0 . 0 0 I}$ \\
& Postop & $12.97 \pm 1.42$ & $13.29 \pm 1.20$ & $11.47 \pm 1.58$ & 0.092 \\
Leptin $(\mathrm{ng} / \mathrm{ml})$ & Preop & $5.03 \pm 0.86$ & $5.52 \pm 0.76$ & $4.41 \pm 0.41$ & $\mathbf{0 . 0 4 8}$ \\
& Postop & $5.05 \pm 0.75$ & $4.14 \pm 0.30$ & $\mathbf{0 . 0 0 8}$ \\
\hline
\end{tabular}

GP: gastric plication; Postop: 30 days after the operation; Preop: before operation; SG: sleeve gastrectomy. Bold values are statistically significant.

for one day. All of the distal portions of the material containing the glandular tissue were sampled. The tissue parts were embedded in paraffin blocks and 5- $\mu \mathrm{m}$-thick paraffin sections were obtained for hematoxylin-eosin and Masson's trichrome stain. Microscopic examination of all tissues was done in Bagcilar Training and Research Hospital Pathology Laboratory. Foveolar hyperplasia (FH) and glandular cystic dilatation (CGD) were examined in the fundus, corpus, and antral part of the specimens. Scoring was done as semi-quantitatively $(0=$ nope, $1=$ mild, $2=$ moderate, and $3=$ severe). Fibrosis of the tissue was scored $(0=$ nope, $1=$ mild, $2=$ moderate, and $3=$ severe).

\section{Immunohistochemical evaluation}

Anti-ghrelin, anti-leptin, and anti-gastrin antibodies (Rabbit polyclonal IgG-abcam, Heidelberg, Germany) were administered on lysine-coated slides for the immunohistochemical examination of the tissues. All the tissues were studied as a positive control. Cells showing immunoreactivity were counted in the fundus, corpus, and antrum of the stomach. The immunoreactive cells were calculated in five different most intensely stained regions and the average was calculated by dividing it by five under low magnification. The average value was obtained in this way. All tables of immunohistochemical analysis of all rats were done by counting the immunoreactive cells.

\section{Statistical analysis}

In this study, statistical analysis was done by NCSS (Number Cruncher Statistical System) 2007 statistical software program (Utah, Heidelberg, USA). A Kruskal-Wallis test and descriptive statistical methods (mean, standard deviation) were used for the evaluation of data and comparison between groups, Dunn's multiple comparison test was used for subgroup comparison, and a Chi-square test was used for the comparison of qualitative data. A $p$-value of $<0.05$ was considered statistically significant.

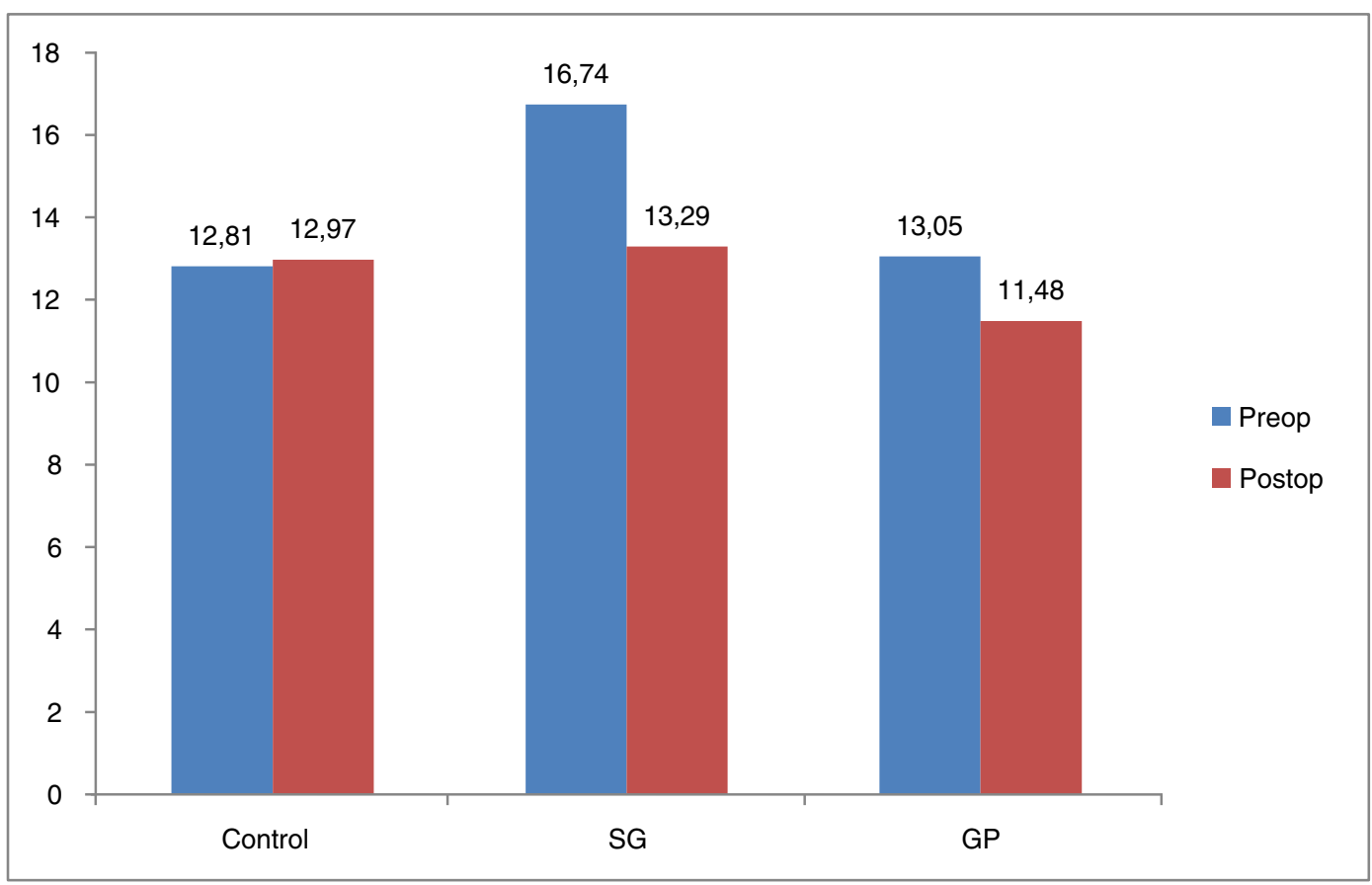

Graphic 1. Ghrelin levels (ng/ml). SG: sleeve gastrectomy, GP: gastric plication. 


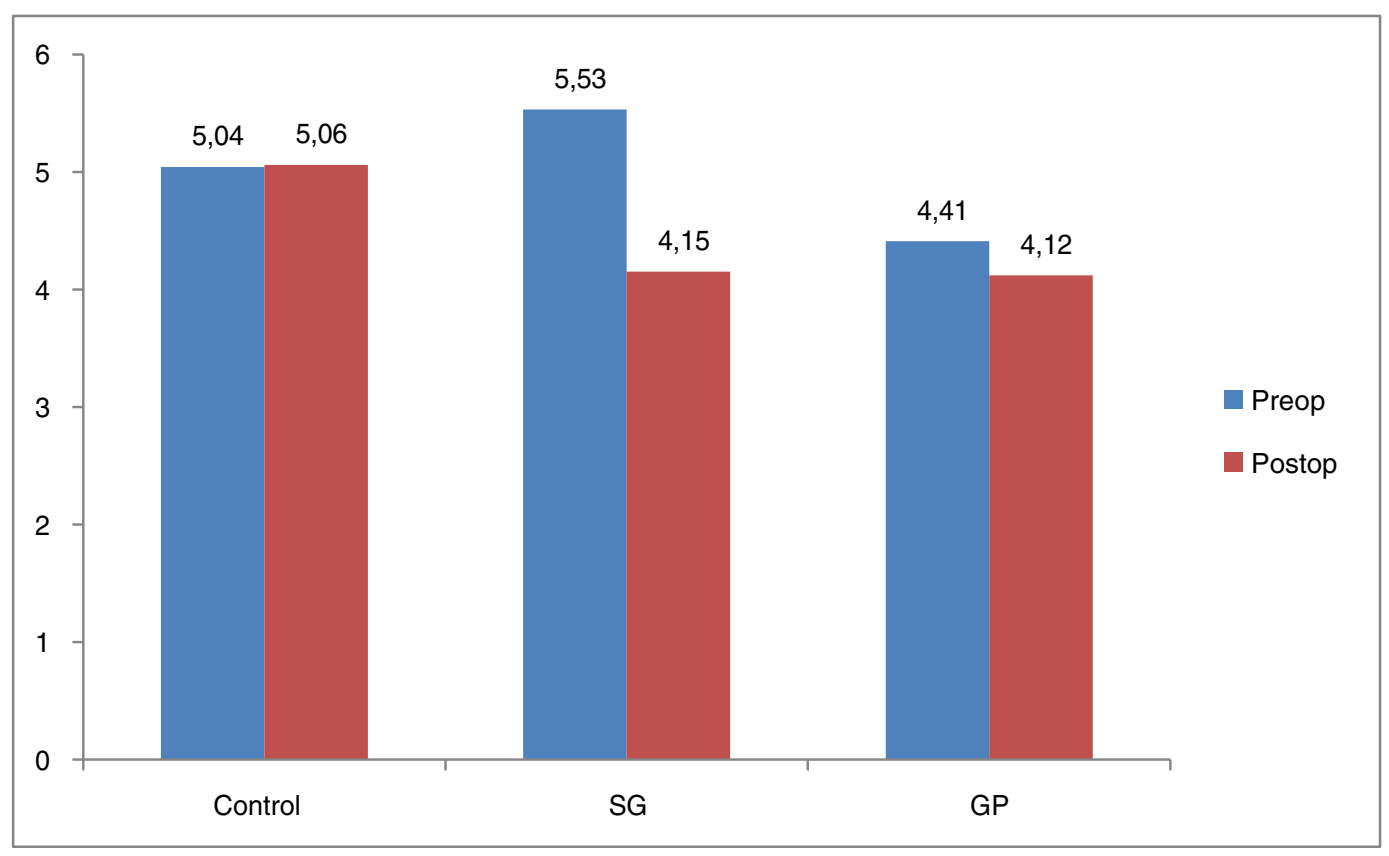

Graphic 2. Leptin levels (ng/ml). SG: sleeve gastrectomy, GP: gastric plication.

\section{Results}

Postoperative gastrin values of the SG group had increased significantly $(p=0.011)$. However, there was no significant change in gastrin values post-operatively in the GP group ( $p=0.964)$ (Table 1).

Ghrelin and leptin levels decreased in both groups (ghrelin/leptin SG group: $p=0.001 / p=0.002$, GP group: $p=0.006 / p=0.624)$. However, the decrease in leptin values was not significant $(p=0.624)$ (Table 1 and Graphics 1 and 2).

Weight loss was $10 \%$ in the SG group and $6.3 \%$ in the GP group ( $p=0.016$ for SG and $p=0.068$ for GP group) (Table 2).

$\mathrm{FH}$, cystic glandular dysplasia (CGD), and the grade of fibrosis were significantly higher in both groups than in the control group ( $p=0.008, p=0.001, p=0.001)$. Although this increase was higher in the SG group, there was no significant difference between the groups $(p>0.05)$ (Table 3 and Fig. 2).

Table 2. Average weight of rats before and 30 days after the operation

\begin{tabular}{lcccc}
\hline & Control group & SG group & GP group & $P$ \\
\hline $\begin{array}{l}\text { Preop } \\
\text { (gr weight) }\end{array}$ & $648.83 \pm 48.26$ & $633.83 \pm 40.65$ & $581.50 \pm 28.97$ & $\mathbf{0 . 0 2 7}$ \\
$\begin{array}{l}\text { Postop } \\
\text { (gr weight) }\end{array}$ & $628 \pm 42.40$ & $560.33 \pm 32.86$ & $544.17 \pm 62.40$ & $\mathbf{0 . 0 1 8}$ \\
\hline
\end{tabular}

GP: gastric plication; Postop: 30 days after the operation, Preop: before operation, SG: sleeve gastrectomy. Bold values are statistically significant.
The immunohistochemical examination revealed that antral gastrin values were significantly higher in the SG group compared with the control and GP groups ( $p=0.027, p=0.004$ ). However, there was no significant difference between the control group and the GP group $(p=0.646)$.

The ghrelin and leptin levels of the SG and GP groups were significantly lower than those of the control group (ghrelin/leptin: SG group: $p=0.0001 / p=0.0001$, GP group: $p=0.0001 / p=0.0001$ ) (Table 4 and Fig. 3).

Table 3. Distribution of FH, CGD, and fibrosis among the groups

\begin{tabular}{|c|c|c|c|c|c|}
\hline & & $\begin{array}{c}\text { Control } \\
\text { group (\%) }\end{array}$ & $\begin{array}{c}\text { SG group } \\
(\%)\end{array}$ & $\begin{array}{l}\text { GP group } \\
(\%)\end{array}$ & $P$ \\
\hline \multirow[t]{4}{*}{$\mathrm{FH}$} & Minimal & $6(100.00)$ & I (16.70) & I (16.70) & 0.008 \\
\hline & Mild & $0(0.00)$ & I (16.70) & $4(66.70)$ & \\
\hline & Moderate & $0(0.00)$ & $2(33.30)$ & I (16.70) & \\
\hline & Severe & $0(0.00)$ & $2(33.30)$ & $0(0.00)$ & \\
\hline \multirow[t]{4}{*}{ CGD } & Minimal & $6(100.00)$ & I (16.70) & $0(0.00)$ & 0.001 \\
\hline & Mild & $0(0.00)$ & I (16.70) & $5(83.30)$ & \\
\hline & Moderate & $0(0.00)$ & $2(33.30)$ & I (I6.70) & \\
\hline & Severe & $0(0.00)$ & $2(33.30)$ & $0(0.00)$ & \\
\hline \multirow[t]{4}{*}{ Fibrosis } & Minimal & $6(100.00)$ & $0(0.00)$ & $0(0.00)$ & 0.0001 \\
\hline & Mild & $0(0.00)$ & $0(0.00)$ & $4(66.70)$ & \\
\hline & Moderate & $0(0.00)$ & $3(50.00)$ & $2(33.30)$ & \\
\hline & Severe & $0(0.00)$ & $3(50.00)$ & $0(0.00)$ & \\
\hline
\end{tabular}

CGD: cystic glandular dysplasia, FH: foveolar hyperplasia, GP: gastric plication, SG: sleeve gastrectomy. Bold values are statistically significant. 


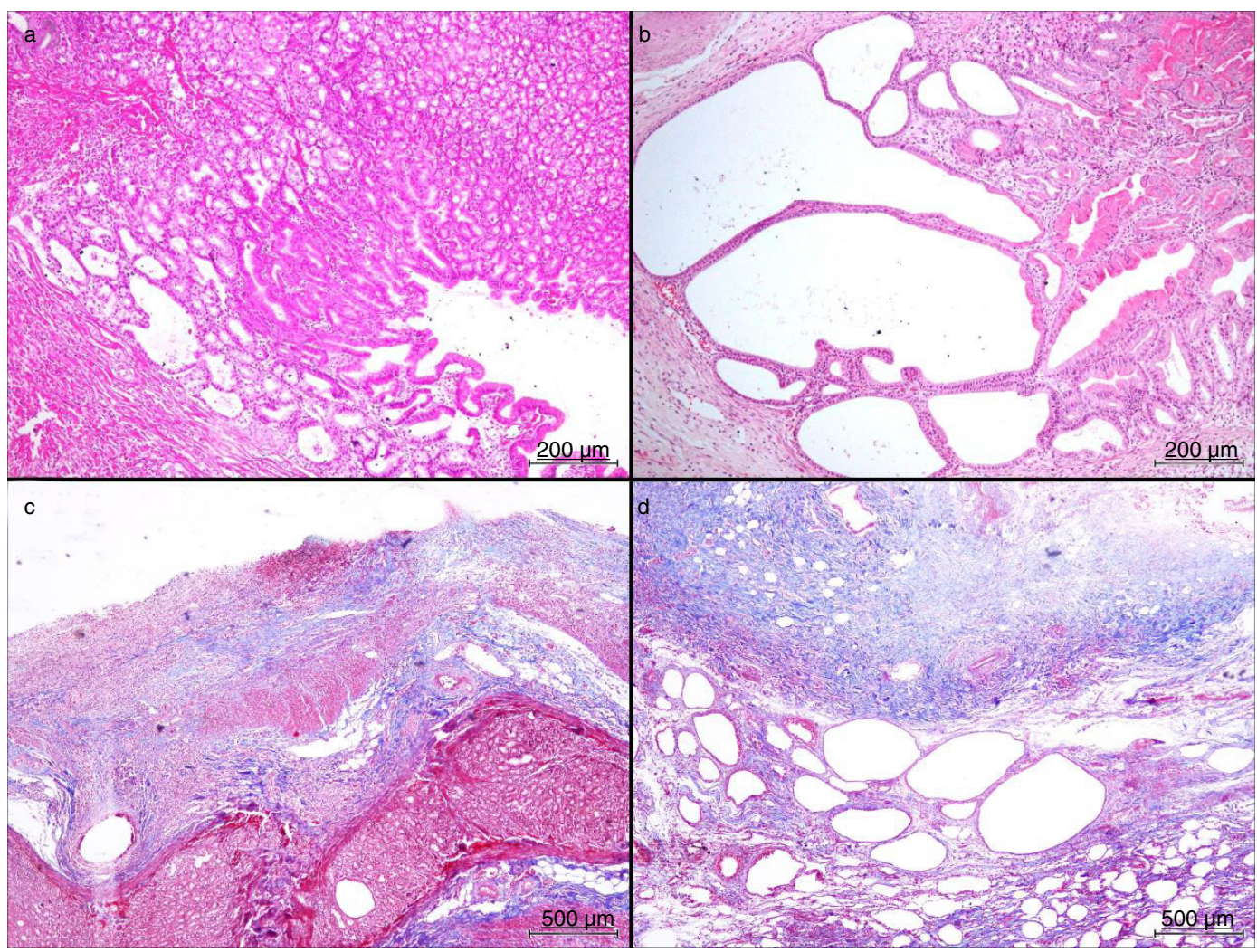

Fig. 2. There is prominent foveolar hyperplasia $(\mathrm{a}, \mathrm{H} \& \mathrm{E}, \times 100)$ and also marked gastric cystic dilatation in the SG group (b, H\&E, $\times 100)$ on histopathological examination. We see mild fibrosis on the serosal surface of the GP group (c, Masson's trichrome stain, $\times 40)$. Contrarily, there is prominent fibrosis on the serosal surface of the GP group, which manifest as blue colored areas on histochemical examination (d, Masson's trichrome stain, $\times 40)$ (GP: gastric plication, SG: sleeve gastrectomy).

\section{Discussion}

Our study aimed to compare the metabolic efficiency and histopathological results of both restrictive surgical methods, SG and GP. Obesity is considered to be a major health issue all over the world. It can be defined as the accumulation of abnormal or excessive fat tissue in the body that negatively impacts health. Patients with a BMI of $40 \mathrm{~kg} / \mathrm{m}^{2}$ or more are considered morbidly obese $(1,4)$.

Besides diet, changes in dietary habits, drugs, and surgical methods provide long and effective treatment for

Table 4. Gastrin, ghrelin, and leptin values of the groups

\begin{tabular}{lrrrl}
\hline & Control group & SG group & GP group & $P$ \\
\hline Gastrin antrum & $54.17 \pm 2.79$ & $60.5 \pm 2.35$ & $55.67 \pm 3.39$ & $\mathbf{0 . 0 0 4}$ \\
Ghrelin fundus & $51.5 \pm 5.47$ & $25.33 \pm 5.32$ & $28 \pm 5.62$ & $\mathbf{0 . 0 0 0 I}$ \\
Ghrelin corpus & $40.83 \pm 4.79$ & $21.5 \pm 4.76$ & $22.5 \pm 3.62$ & $\mathbf{0 . 0 0 0 I}$ \\
Ghrelin antrum & $31.33 \pm 4.72$ & $18.33 \pm 3.88$ & $20.33 \pm 4.18$ & $\mathbf{0 . 0 0 0 I}$ \\
Leptin fundus & $42.17 \pm 3.37$ & $28 \pm 4.86$ & $28.67 \pm 4.13$ & $\mathbf{0 . 0 0 0 I}$ \\
Leptin corpus & $22.17 \pm 3.49$ & $16.83 \pm 2.93$ & $18.83 \pm 2.48$ & $\mathbf{0 . 0 2 4}$ \\
\hline
\end{tabular}

GP: gastric plication; SG: sleeve gastrectomy. Bold values are statistically significant. the management of obesity (5). Maklin et al. (8) reported that surgery is advantageous in terms of cost-effectiveness in dealing with obesity and its morbidities.

SG and GP have been performed with gradually increasing frequency in recent years. Both techniques can be successfully applied laparoscopically (9). SG, first described by Marceau et al. (10) in 1993, was initially applied as a first phase of biliopancreatic diversion, duodenal switch, and gastric bypass operations. Since 2003 , it has been applied alone. It involves resection of the greater curvature of the stomach from antrum to angle of His throughout latarjet nerve (10).

GP was first described by Taleppour and Amoli in 2007. In this technique, greater curvature of the stomach is plicated over itself by non-absorbable sutures with the help of a 32-36 F plug catheter, after the liberalization of the greater curvature (11).

Most of the gastrin is produced and secreted by antral $\mathrm{G}$ cells of the stomach. The most important function of the gastrin is the stimulation of gastric acid from parietal cells of the fundus (12). All studies have demonstrated that the gastrin levels of the patients do not change or decrease after bypass procedures, except the jejunoileal bypass (13). In our study, the gastrin levels of the SG 


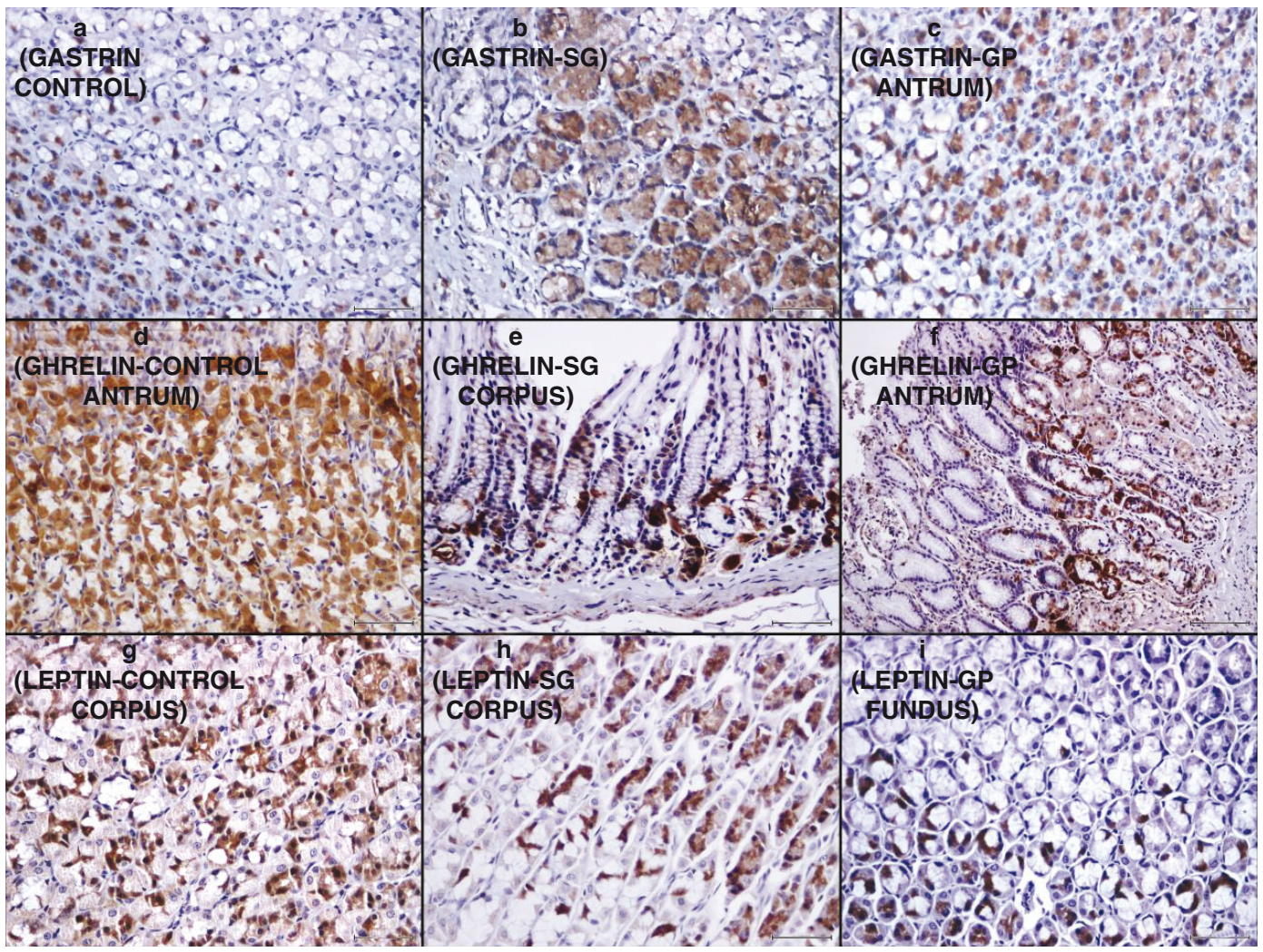

Fig. 3. Gastrin immunoreactivity created by gastrin dye is more evident in the SG group than the GP and control groups on immunohistochemical examination $(\mathrm{a}-\mathrm{c}, \times 400)$. There is less ghrelin immunoreactivity in both the SG and GP groups compared with the control group (d, e, $\times 400 ; \mathrm{f}, 200)$. Similarly, there is less leptin immunoreactivity in both the SG and GP groups compared with the control group $(\mathrm{g}-\mathrm{i}, \times 400)(\mathrm{GP}$ : gastric plication, $\mathrm{SG}$ : sleeve gastrectomy).

group were increased significantly $(p=0.011)$, but there was no significant change in the GP group $(p=0.964)$.

Ghrelin was discovered by Davis and described by Kojima in $1991(14,15)$. It is expressed by specialized enterochromaffin cells located in the fundal region of the stomach (16). Whang and Liu published an article in 2008 , claiming that there is a proportional relation between BMI and ghrelin decrease (17). Leptin is produced and secreted into blood from adipocytes (18). The serum leptin level is directly proportional to the amount of body fat and is increased in obese patients (19). It has been found that the plasma leptin level is reduced in people who lose weight (20). According to the study by Considine et al., (21) $10 \%$ of weight loss causes a $53 \%$ decrease in leptin level, and the leptin levels increase again up to $70 \%$ of initial values after a 4 -week period of weight loss. In our study, the ghrelin and leptin values of both groups (SG and GP) were significantly reduced after surgery, according to the biochemical and histopathological findings.

Although FH can be seen in all types of gastritis, it is more prominent in chemical gastritis (22). There is a debate about whether $\mathrm{FH}$ is a precursor lesion of the hyperplastic polyps (23-25). There is no malignant degeneration in $\mathrm{FH}$, so it is important to distinguish these lesions from hyperplastic lesions (26). Orlowska followed 483 patients with hyperplastic polyps and 268 patients with FH for 2 years and 8 months, and detected 2\% focal carcinoma in the hyperplastic polyp group. On the contrary, there was no carcinoma in the FH group (26). CGD occurs due to hyperplasia and cystic dilatation of submucosal glands extending into the submucosal layer (27). Although it is accepted as a benign lesion, there is still debate about its malignancy potential (28-31). This relation between CGD and malignancy indicates that a common factor causes both pathologies (32). In our study, FH, CGD, and fibrosis levels were significantly higher in both the SG and GP groups than in the control group ( $p=0.008, p=0.001, p=0.001$ ). However, the $\mathrm{SG}$ group has higher values compared with the GP group. This may be due to the gastric resection in the SG group.

\section{Conclusion}

Although GP does not cause weight loss as much as SG, similar metabolic activity may be provided due to the decrease in ghrelin and leptin levels after the operation. Histopathological findings revealed that SG and GP have similar results in terms of fibrosis levels, FH, and CGD formation. 


\section{Conflict of interest and funding}

The authors have not received any funding or benefits from industry or elsewhere to conduct this study.

\section{References}

1. Ewing BT, Thompson MA, Wachtel MS, Frezza EE. A costbenefit analysis of bariatric surgery on the South Plains region of Texas. Obes Surg 2011; 21: 644-9.

2. Blackburn GL, Kanders BS. Medical evaluation and treatment of the obese patients with cardiovascular disease. Am J Cardiol 1987; 60: 55-8.

3. Laing ST, Smulevitz B, Vatcheva KP, Rahbar MH, Reininger B, McPherson DD, et al. Subclinical atherosclerosis and obesity phenotypes among Mexican Americans. J Am Heart Assoc 2015; 4(3): 001540.

4. Domienik-Karlowicz J, Dzikowska-Diduch O, Lisik W, Chmura A, Pruszczyk P. Short-term cardio metabolic risk reduction after bariatric surgery. Hellenic J Cardiol 2015; 56(1): 61-5

5. López-NavaBrevière G, Bautista-Castaño I, Jimenez A, de Grado T, Fernandez-Corbelle JP. The Primary Obesity Surgery Endolumenal (POSE) procedure: one-year patient weight loss and safety outcomes. Surg Obes Relat Dis 2015; 11(4): 861-5.

6. Benaiges D, Goday A, Pedro-Botet J, Más A, Chillarón JJ, Flores-Le Roux JA. Bariatric surgery: to whom and when? Minerva Endocrinol 2015; 40(2): 119-28.

7. Verdi D, Prevedello L, Albanese A, Lobba A, Foletto M. Laparoscopic gastric plication (LGCP) vs sleeve gastrectomy (LSG): a single institution experience. Obes Surg 2015; 25(9): 1653-7.

8. Maklin S, Malmivaara A, Linna M, Victorzon M, Koivukangas V, Sintonen H. Cost-utility of bariatric surgery for morbid obesity in Finland. Br J Surg 2011; 98: 1422-9.

9. Shen D, Ye H, Wang Y, Ji Y, Zhan X, Zhu J, et al. Comparison of short-term outcomes between laparoscopic greater curvature plication and laparoscopic sleeve gastrectomy. Surg Endosc 2013; 27(8): 2768-74.

10. Marceau P, Hould FS, Simard S, Lebel S, Bourque RA, Potvin $\mathrm{M}$, et al. Biliopancreatic diversion with duodenal switch. World J Surg 1998; 22: 947-54.

11. Talebpourand M, Amoli BS. Laparoscopic total gastric vertical plication in morbid obesity. J Laparoendosc Adv Surg Tech A 2007; 17(6): 793-8.

12. Dacha S, Razvi M, Massaad J, Cai Q, Wehbi M. Hypergastrinemia. Gastroenterol Rep (Oxf) 2015; 3(3): 201-8.

13. Ashrafian H, le Roux CW. Metabolic surgery and gut hormones - a review of bariatric entero-humoral modulation. Physiol Behav 2009; 97(5): 620-31.

14. Davis JC. The relation between the pancreatic alpha cells and certain cells in the gastric mucosa. J Pathol Bacteriol 1954; 67: 237-40.

15. Kojima M, Hosoda H, Date Y. Ghreline: discovery of natural endogenous ligand for the growth hormone secretgogue receptor. Trends Endocrinol Metab 2001; 12: 118-22.

16. AydIn S. Ghrelin hormonunun keșfi: AraștIrmalarI ve klinik uygulamalarI. Türk biyokimya Dergisi 2007; 32: 76-89.
17. Wang HT, Lu QC, Wang Q, Wang RC, Zhang Y, Chen HL, et al. Role of duodenum in regulation of plasma ghrelin level and body mass index after subtotal gastrectomy. Zhonghua Wei ChangWai Ke ZaZhi 2008; 11: 436-9.

18. Tadokoro S, Ide S, Tokuyama R, Umeki H, Tatehara S, Kataoka S, et al. Leptin promotes wound healing in the skin. PLoS One 2015; 10(3): 1-16.

19. Dagogo JS, Fanelli C, Paramore D, Brothers J, Landt M. Plasma leptin and insulin relationships in obese and nonobese humans (abstract). Diabetes 1996; 45: 695-8.

20. Zhang F, Basinski MB, Beals JM, Briggs SL, Churgay LM, Clawson DK, et al. Crystal structure of the obese protein leptinE100. Nature 1997; 387: 206-9.

21. Considine R, Sinha M, Heiman M, Kriauciunas A, Stephens T, Nyce M, et al. Serum Immunoreactive-Leptin Concentrations in Normal-Weight and Obese Humans. N Engl J Med 1996; 334(5): 292-95.

22. Price AB. The Sydney System: histological division. J Gastroenterol Hepatol 1991; 6: 209-22.

23. Oberhuber G, Stolte M. Gastric polyps: an update of their pathology and biological significance. Virchows Arch 2000; 437: $581-90$.

24. Rattan J, Arber N, Tiomny E, Moshkowitz M, Chapsky Y, Baratz M, et al. Gastric polypoid lesions-an eight-year study. Hepato-Gastroenterology 1993; 40: 107-9.

25. Elster K. Histologic classification of gastric polyps. Curr Top Pathol 1976; 63: 77-93.

26. Orlowska J, Jarosz D, Pachlewski J, Butruk E. Malignant transformation of benign epithelial gastric polyps. Am J Gastroenterol 1995; 90: 2152-9.

27. Machicado J, Shroff J, Quesada A, Jelinek K, Spinn MP, Scott LD, et al. Gastritis cystic profunda: Endoscopic ultrasound findings and review of the literature. Endosc Ultrasound 2014; 3(2): 131-4.

28. Wang L, Yan H, Cao DC, Huo L, Huo HZ, Wang B, et al. Gastritis cystic profunda recurrence after surgical resection: 2-year follow-up. World J Surg Oncol 2014; 12: 133.

29. Fonde EC, Rodning CB. Gastritis cystica profunda. Am J Gastroenterol 1986; 81: 459-64.

30. Mitomi H, Iwabuchi K, Amemiya A, Kaneda G, Adachi K, Asao T. Immunohistochemical analysis of a case of gastritis cystic profunda associated with carcinoma development. Scand J Gastroenterol 1998; 33: 1226-9.

31. Park JS, Myung SJ, Jung HY, Yang SK, Hong WS, Kim JH, et al. Endoscopic treatment of gastritis cystic polyposa found in an unoperated stomach. Gastrointest Endosc 2001; 54: 101-3.

32. Wang TC, Dangler CA, Chen D, Goldenring JR, Koh T, Raychowdhury R, et al. Synergistic interaction between hypergastrinemia and Helicobacter infection in a mouse model of gastric cancer. Gastroenterology 2000; 118: 36-47.

*Osman Bilgin Gulcicek

Istanbul Bagcilar Training and Research Hospital

Istanbul 34200

Turkey

Email: drosmanbilgin@hotmail.com 